\title{
A comparative study of national innovation efficiency based on SFA
}

\author{
Shu Zhu ${ }^{\mathrm{a}^{*}}$, Yong $Q i^{b}$ \\ ${ }^{\text {a }}$ School of Economic\& Management,Nanjing University of Science\& Technology,china \\ ${ }^{\mathrm{b}}$ School of Economic\& Management,Nanjing University of Science\& Technology,china \\ *Corresponding author: Shu Zhu,postgraduate,824834108@qq.com
}

\begin{abstract}
Based on the two-stage theory of innovation, this paper divides the innovation efficiency into R \& D efficiency and output efficiency.Using the stochastic frontier analysis method (SFA) to evaluate and compare the innovation efficiency of the world's major innovative countries and BRIC countries.It is found that China's R \& D efficiency is at a low level, the output efficiency level is higher.

In the empirical analysis, it is also found that foreign direct investment has no direct effect on R \& D efficiency and has negative influence on output efficiency; market openness has a positive impact on R \& D efficiency and output efficiency; government R \& D investment has a negative impact on R \& D efficiency and output efficiency. Finally, suggestions are made.
\end{abstract}

Key words: SFA; innovation efficiency; innovation national; BRIC; R\&D efficiency; Output efficiency

\section{Introduction}

In the context of innovative globalization, countries will build a national innovation system as an important means to improve national competitiveness. However, in the process of building an innovation-oriented country, there is still a certain gap between the BRIC countries and the innovation capacities of the major innovative countries. At present, there are more than 20 recognized countries in the world (Liu Yun ${ }^{1}$ ), and the National Innovation Index Report released in June 2016 shows that the top 10 global innovation countries are the United States, Japan, Switzerland, Korea, Denmark, Germany, Sweden, the Netherlands and Singapore.In the five BRIC countries, in addition to China ranked 18th, the other countries are still more ranked. Therefore, it is of practical significance to evaluate and compare the innovation efficiency of the world's major innovative countries and BRIC countries, and to improve the capability of independent innovation in China. 
Since Freeman ${ }^{2}$ first proposed the concept of national innovation system ${ }^{2}$, both domestic and foreign scholars have conducted in-depth study. Many scholars have measured the efficiency of national innovation (e.g. Eric C. Wang ${ }^{3}$, Chiang-Ping Chen et al. ${ }^{4}$, Jiancheng Guan et al. ${ }^{5}$, Kravchenko $\mathrm{N} \mathrm{A}^{6}$ ).However, foreign scholars focus on the level of innovation efficiency of developed countries, domestic scholars have less research on the innovation efficiency at the national level, and the data are mostly before 2010, ignoring the comparative study of the BRICS countries similar to those in China. Therefore, this paper will compare the efficiency of the ten major innovative countries and five BRICs to understand China's current level of innovation efficiency and its level in fifteen countries.

\section{Empirical analyses}

\subsection{Mathematical formulas and equations}

Table 1 - National Innovation Efficiency Evaluation Index System

\begin{tabular}{|l|l|l|l|}
\hline $\begin{array}{l}\text { Firstary } \\
\text { indicators }\end{array}$ & Secondary indicators & Indicator description & Data Sources \\
\hline \multirow{5}{*}{$\begin{array}{l}\text { Input } \\
\text { indicators }\end{array}$} & Manpower input $L_{i t}$ & $\begin{array}{l}\text { R \& D staff full time equivalent } \\
\text { (person / year) }\end{array}$ & OECD official website \\
\cline { 2 - 4 } & Fapital investment $K_{i t}$ & $\begin{array}{l}\text { R \& D expenditure total (billion, } \\
\text { dollars) }\end{array}$ & OECD official website \\
\cline { 2 - 4 } & Foreign investment $Z_{1}$ & $\begin{array}{l}\text { Foreign direct investment (billion, } \\
\text { dollar) }\end{array}$ & OECD official website \\
\cline { 2 - 4 } & Market openness $Z_{2}$ & $\begin{array}{l}\text { Total imports and exports (billion, } \\
\text { US dollars) }\end{array}$ & $\begin{array}{l}\text { World Bank official } \\
\text { website }\end{array}$ \\
\cline { 2 - 5 } & Government investment & $\begin{array}{l}\text { Government-funded R \& D Total } \\
\text { (billion, US \$) }\end{array}$ & OECD official website \\
\hline \multirow{3}{*}{$\begin{array}{l}\text { Output } \\
\text { indicators }\end{array}$} & R \& D output $S_{i t}$ & Number of three patents (one) & OECD official website \\
\cline { 2 - 4 } & Innovation output & $\begin{array}{l}\text { High-tech industry added value } \\
\text { (million, USD) }\end{array}$ & $\begin{array}{l}\text { NSF 《S\&E } \\
\text { Indicators》 }\end{array}$ \\
\hline
\end{tabular}

There are usually two methods of technical efficiency measurement, one is the nonparametric method (such as DEA); the second, is the parameter method.The most common is SFA, which has the advantage of decomposing the actual production unit from the frontier surface into uncontrollable random errors and controllable technology inefficiencies, using econometric methods to estimate the frontier production function. The efficiency and consistency of the measured efficiency are ensured by the inefficiency term and the random error term, and the effect of the random error term on the individual efficiency is considered. Therefore, this paper uses the stochastic frontier analysis method to carry out the national innovation strategy efficiency evaluation. The specific model is:

$$
\begin{aligned}
& L N\left(S_{\text {it }}\right)=\beta_{0}+\beta_{1} L N\left(L_{i t}\right)+\beta_{2} L N\left(K_{i t}\right)+v_{i t}-\mu_{i t} \\
& T E_{i t}=\exp \left(-\mu_{i t}\right)
\end{aligned}
$$




$$
\gamma=\frac{\sigma^{2}}{\sigma_{v}^{2}+\sigma_{\mu}^{2}}
$$

The evaluation index system is shown in Table 1:

\section{Empirical results}

Before the empirical analysis,we must first deal with the data: (1) Because of the absence of data for individual years in individual countries, this paper uses the mean method, ie, the average of the data before and after the missing data is used as the data for the missing year.(2) Due to the lag of innovation, in accordance with international practice for two years lag behind the patent, the economic results lag one year, that is, the output of the output indicators selected 2008 - 2014 data, patent output indicators selected 2007 - 2013 data, other Input Indicator Select data for 2005 - 2011.(3) Since the calculation result of the year is large, the calculation result of efficiency is expressed by stage 1 to stage 7.For example, the efficiency of R \& D in Phase 1 uses the 2005 output of the 2007 patent output, the output efficiency of phase 1 using the 2005 input of economic output in 2008, and so on.

\subsection{R \& D efficiency}

Using Frontier4.1 software to measure the data, the R \& D efficiency is as follows:

It can be seen from Table 2 that $\gamma=0.8497$,close to 1 ,and the LR test value is tested at a significance level of $1 \%$,indicating that the inefficiency term accounts for the deviation of the production unit from the frontier,it is reasonable to use SFA to analyse panel data in 15 countries. $\beta_{1}=1.5270$, indicating that $\mathrm{R} \& \mathrm{D}$ staff full-time equivalent of R \& D output has a significant positive impact. $\beta_{2}=-0.4844$, indicating that the total expenditure on $\mathrm{R} \& \mathrm{D}$ expenditure has a significant negative impact on $\mathrm{R} \& \mathrm{D}$ output. This may be due to the use of R \& D costs unreasonable situation, the use of funds is not high efficiency.

$\delta_{1}$ has not passed the test, indicating that foreign direct investment has no direct effect on R \& D efficiency. $\delta_{2}$ is negative, indicating that the market openness of the R \& D efficiency has a significant positive impact. $\delta_{3}$ is positive, indicating that government investment has a significant negative impact on R \& D efficiency, it may be because the government simply to increase investment in R \& D easily lead to industry innovation on government investment dependencies, reducing the ability of independent innovation .

As can be seen from Table 3, the top three countries with R \& D efficiency in 15 countries were Japan, the United States and Switzerland, and opened a large gap with other countries. Most of the innovative countries have not grown significantly in seven years, mostly in the 
original level of efficiency hovering, of which Singapore's R \& D efficiency is only about 0.75.In the BRIC countries, India's R \& D efficiency has grown rapidly and has reached 0.9740 in Phase 7, which is almost the same as in the United States. While the other four countries R \& D efficiency levels are low, especially China's seven-year average R \& D efficiency is only 0.6495 .However,from the comparison of the growth trends of the five countries, the R \& D efficiency of the BRICs has steadily improved over time.

Table 2 - Measurement of R \& D Efficiency

\begin{tabular}{cccc}
\hline Parameter & Coefficient & Standard deviation & t-test \\
\hline$\beta_{0}$ & -5.3166 & 1.2862 & $-4.1337^{* * *}$ \\
$\beta_{1}$ & 1.5270 & 0.2626 & $5.8157^{* * *}$ \\
$\beta_{2}$ & -0.4844 & 0.2828 & $-1.7129^{*}$ \\
$\delta_{0}$ & -3.2125 & 6.6906 & $-1.8401^{*}$ \\
$\delta_{1}$ & -0.0021 & 0.0524 & -0.0407 \\
$\delta_{2}$ & -4.4361 & 0.5696 & $-7.7878^{* * *}$ \\
$\delta_{3}$ & 1.1098 & 0.2671 & $4.1546^{* * *}$ \\
sigma-squared & 13.3230 & 10.4858 & $1.7206^{*}$ \\
$\gamma$ & 0.8497 & 0.0000 & $273937.12^{* * *}$ \\
LR & & $73.41^{* * *}$ & \\
\hline
\end{tabular}

Table 3 - R \& D Efficiency

\begin{tabular}{|c|c|c|c|c|c|c|c|c|c|}
\hline Country & 1 & 2 & 3 & 4 & 5 & 6 & 7 & Average & Sort \\
\hline $\begin{array}{l}\text { United } \\
\text { States }\end{array}$ & 0.9763 & 0.9753 & 0.9760 & 0.9658 & 0.9618 & 0.9734 & 0.9754 & 0.9720 & 3 \\
\hline Japan & 0.9871 & 0.9779 & 0.9837 & 0.9993 & 0.9958 & 0.9951 & 0.9952 & 0.9906 & 1 \\
\hline Switzerland & 0.9940 & 0.9883 & 0.9821 & 0.9913 & 0.9825 & 0.9862 & 0.9847 & 0.9870 & 2 \\
\hline Korea & 0.9003 & 0.8824 & 0.8863 & 0.8941 & 0.8843 & 0.8833 & 0.8855 & 0.8880 & 8 \\
\hline Denmark & 0.9189 & 0.9345 & 0.8849 & 0.7913 & 0.7812 & 0.7949 & 0.8003 & 0.8437 & 9 \\
\hline Germany & 0.9336 & 0.9271 & 0.9258 & 0.9155 & 0.9077 & 0.9021 & 0.8987 & 0.9158 & 4 \\
\hline Sweden & 0.9287 & 0.9151 & 0.9173 & 0.8853 & 0.8808 & 0.8893 & 0.8846 & 0.9002 & 7 \\
\hline $\begin{array}{c}\text { United } \\
\text { Kingdom }\end{array}$ & 0.8275 & 0.8205 & 0.8208 & 0.8188 & 0.8211 & 0.8205 & 0.8246 & 0.8220 & 10 \\
\hline Netherlands & 0.9100 & 0.9135 & 0.9131 & 0.8845 & 0.9163 & 0.9035 & 0.8894 & 0.9043 & 6 \\
\hline Singapore & 0.7567 & 0.7547 & 0.7397 & 0.7439 & 0.7443 & 0.7275 & 0.7532 & 0.7457 & 12 \\
\hline China & 0.6082 & 0.6221 & 0.6554 & 0.6572 & 0.6547 & 0.6731 & 0.6760 & 0.6495 & 13 \\
\hline Brazil & 0.7355 & 0.7748 & 0.7781 & 0.7537 & 0.7483 & 0.7760 & 0.7945 & 0.7659 & 11 \\
\hline Russia & 0.3987 & 0.3753 & 0.4179 & 0.4232 & 0.4252 & 0.4333 & 0.4331 & 0.4152 & 15 \\
\hline India & 0.8211 & 0.8784 & 0.8939 & 0.9188 & 0.9400 & 0.9602 & 0.9740 & 0.9123 & 5 \\
\hline South Africa & 0.5756 & 0.6199 & 0.5582 & 0.5409 & 0.5943 & 0.5503 & 0.5438 & 0.5690 & 14 \\
\hline Average & 0.8181 & 0.8240 & 0.8222 & 0.8122 & 0.8159 & 0.8179 & 0.8209 & 0.8187 & \\
\hline
\end{tabular}

\subsection{Output efficiency}

Using Frontier4.1 software to measure the data, the output efficiency is as follows:

It can be seen from Table 4 that $\gamma=0.6066$,close to 1 , and the LR test value is tested at a significance level of $1 \%$,indicating that the inefficiency term accounts for the deviation of the production unit from the frontier,it is reasonable to use SFA to analyse panel data in 15 countries. $\beta_{0}, \beta_{1}$ and $\beta_{2}$ are tested by significant tests from the total $\mathrm{R} \& \mathrm{D}$ expenditure and the 
$\mathrm{R}$ \& D staff full-time factor. Which $\beta_{1}=0.4056$, indicating that $\mathrm{R} \& \mathrm{D}$ staff full-time equivalent of economic output has a significant positive impact. $\beta_{2}=0.2306$, indicating that $R$ \& D expenditure has a significant positive impact on R \& D output..

Table 4 - Measurement of output Efficiency

\begin{tabular}{cccc}
\hline Parameter & Coefficient & Standard deviation & t-test \\
\hline$\beta_{0}$ & 3.8867 & 0.7987 & $4.8661^{* * *}$ \\
$\beta_{1}$ & 0.4056 & 0.0793 & $5.1157^{* * *}$ \\
$\beta_{2}$ & 0.2316 & 0.0562 & $4.1234^{* * *}$ \\
$\delta_{0}$ & 2.3330 & 0.2550 & $9.1489^{* * *}$ \\
$\delta_{1}$ & 0.0354 & 0.0130 & $2.7252^{* *}$ \\
$\delta_{2}$ & -2.8533 & 0.3997 & $-7.1396^{* * *}$ \\
$\delta_{3}$ & 0.5359 & 0.1283 & $4.1771^{* * *}$ \\
sigma-squared & 0.6802 & 0.1315 & $5.1737^{* * *}$ \\
$\gamma$ & 0.6066 & 0.0765 & $7.9293^{* * *}$ \\
LR & & $55.36^{* * *}$ & \\
\hline
\end{tabular}

Table 5 - Output Efficiency

\begin{tabular}{|c|c|c|c|c|c|c|c|c|c|}
\hline Country & 1 & 2 & 3 & 4 & 5 & 6 & 7 & Average & Sort \\
\hline $\begin{array}{l}\text { United } \\
\text { States }\end{array}$ & 0.9880 & 0.9892 & 0.9905 & 0.9914 & 0.9831 & 0.9900 & 0.9930 & 0.9893 & 1 \\
\hline Japan & 0.9703 & 0.9718 & 0.9741 & 0.9802 & 0.9650 & 0.9729 & 0.9789 & 0.9733 & 4 \\
\hline Switzerland & 0.9466 & 0.9398 & 0.9490 & 0.9622 & 0.9544 & 0.9603 & 0.9687 & 0.9544 & 7 \\
\hline Korea & 0.9391 & 0.9421 & 0.9571 & 0.9596 & 0.9416 & 0.9524 & 0.9659 & 0.9511 & 8 \\
\hline Denmark & 0.8610 & 0.8594 & 0.8710 & 0.8650 & 0.8576 & 0.8646 & 0.8668 & 0.8636 & 11 \\
\hline Germany & 0.9860 & 0.9869 & 0.9906 & 0.9925 & 0.9880 & 0.9899 & 0.9924 & 0.9895 & 2 \\
\hline Sweden & 0.8840 & 0.8796 & 0.8866 & 0.9020 & 0.8908 & 0.8988 & 0.9008 & 0.8918 & 9 \\
\hline $\begin{array}{c}\text { United } \\
\text { Kingdom }\end{array}$ & 0.9573 & 0.9653 & 0.9704 & 0.9771 & 0.9631 & 0.9711 & 0.9787 & 0.9690 & 5 \\
\hline Netherlands & 0.8681 & 0.8513 & 0.8190 & 0.9292 & 0.9070 & 0.9229 & 0.9334 & 0.8901 & 10 \\
\hline Singapore & 0.9468 & 0.9502 & 0.9628 & 0.9705 & 0.9642 & 0.9694 & 0.9744 & 0.9626 & 6 \\
\hline China & 0.9756 & 0.9820 & 0.9876 & 0.9913 & 0.9874 & 0.9918 & 0.9947 & 0.9872 & 3 \\
\hline Brazil & 0.8392 & 0.8301 & 0.8400 & 0.8505 & 0.8442 & 0.8431 & 0.8478 & 0.8421 & 12 \\
\hline Russia & 0.8246 & 0.8148 & 0.8365 & 0.8622 & 0.8310 & 0.8539 & 0.8719 & 0.8421 & 13 \\
\hline India & 0.8089 & 0.8131 & 0.8289 & 0.8397 & 0.8284 & 0.8413 & 0.8581 & 0.8312 & 14 \\
\hline South Africa & 0.7531 & 0.7543 & 0.7629 & 0.7654 & 0.7602 & 0.7642 & 0.7679 & 0.7611 & 15 \\
\hline Average & 0.9032 & 0.9020 & 0.9085 & 0.9226 & 0.9111 & 0.9191 & 0.9262 & 0.9132 & \\
\hline
\end{tabular}

$\boldsymbol{\delta}_{1}$ is negative, indicating that the market openness of the output efficiency has a significant positive impact. $\boldsymbol{\delta}_{2}$ is positive, indicating that foreign direct investment has a significant negative impact on output efficiency, which may be due to foreign investment to bring foreign mature products to curb the development of local enterprises. $\boldsymbol{\delta}_{3}$ is positive, indicating that the government investment has a significant negative impact on the efficiency of output, which may be because the government $\mathrm{R} \& \mathrm{D}$ investment will reduce the efficiency of the allocation resulting in reduced output efficiency.

As can be seen from Table 5, the output efficiency of the top three countries in 15 countries followed by the United States, Germany and China, of which China's output efficiency in stage 7 has been as high as 0.9947, ranking first. In general, the output efficiency of ten innovative countries is maintained at a high level, and in addition to China outside the BRIC output efficiency is not too high, and innovation-oriented countries have a greater gap. 


\section{Conclusions}

This paper divides the innovation efficiency into R \& D efficiency and output efficiency, using SFA to evaluate and compare the innovation efficiency of the world's major innovative countries and BRIC countries.Found that China's R \& D efficiency is at a low level,the output efficiency level is higher.In the empirical analysis,it is also found that foreign direct investment has no direct effect on R \& D efficiency and has negative influence on output efficiency;market openness has a positive impact on R \& D efficiency and output efficiency;government R \& D investment has a negative impact on R \& D efficiency and output efficiency.

Based on the above findings, the following recommendations are made:First, establish scientific research performance evaluation system, which focus on improving innovation efficiency, not simply on the number of results as an evaluation.Second, improve the incentive mechanism for enterprises to innovate, to ensure that innovation activities of enterprises to obtain innovative returns, encourage enterprises to independent innovation.Third, focus on the protection of national enterprises.

\section{References}

1. Liu Yun,,Li Zhengfeng, Liu Li,Some Thoughts on the Theory and Policy of International Innovation System of National Innovation System[J].Science and Science and Technology Management, 3 (2010) 61-67

2. FREEMAN CHRISTOPHER.Technology policy and economic performance: lesson from Japan [M]. Print Publishers,1987.

3. Eric C. Wang. R\&D Effiency and Economic Performence: Cross-country Analysis Using the Stochastic Frontier Approach.Journal of Policy Modeling 29, 2007, 345-360.

4. Chiang-Ping Chen, Jin-Li Hu, Chih-Hai Yang. R\&D Effiency and National Innovation System: An International Comparison Using the Distance Function Approac. Bulletin of Economic Research, 2010.

5. Jiancheng Guan, Kaihua Chen. Modeling the relative efficiency of national innovation systems. Research Policy, 2012.

6. Kravchenko $N A$. The problem of measuring and assessing national innovation systems [J]. Problems of Economic Transition, 53 (2011) 61-73. 